\title{
Prioritising Assistance to Brilliant but Needy Students: The Viewpoints of Parents
}

\section{Alfred Kuranchie, Newman Amaning, \& Reindolph Osei Anim}

To Link this Article: http://dx.doi.org/10.6007/IJARBSS/v10-i12/8322

DOI:10.6007/IJARBSS/v10-i12/8322

Received: 10 Novemober 2020, Revised: 30 November 2020, Accepted: 14 December 2020

Published Online: 24 December 2020

In-Text Citation: (Kuranchie et al., 2020)

To Cite this Article: Kuranchie, A., Amaning, N., \& Anim, R. O. (2020). Prioritising Assistance to Brilliant but Needy Students: The Viewpoints of Parents. International Journal of Academic Research in Progressive Education and Development, 9(3), 350-362.

\section{Copyright: (c) 2020 The Author(s)}

Published by Human Resource Management Academic Research Society (www.hrmars.com)

This article is published under the Creative Commons Attribution (CC BY 4.0) license. Anyone may reproduce, distribute, translate and create derivative works of this article (for both commercial and non-commercial purposes), subject to full attribution to the original publication and authors. The full terms of this license may be seen

at: http://creativecommons.org/licences/by/4.0/legalcode

$$
\text { Vol. 10, No. 12, 2020, Pg. } 350 \text { - } 362
$$

Full Terms \& Conditions of access and use can be found at http://hrmars.com/index.php/pages/detail/publication-ethics 


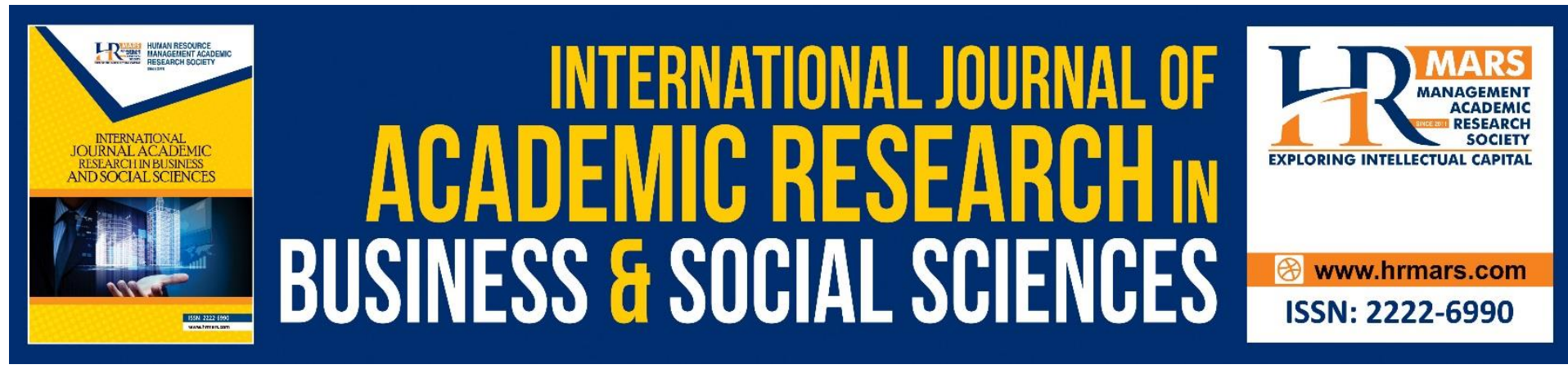

\title{
Prioritising Assistance to Brilliant but Needy Students: The Viewpoints of Parents
}

\author{
Alfred Kuranchie ${ }^{1}$, Newman Amaning ${ }^{2}$, \& Reindolph Osei Anim ${ }^{3}$ \\ ${ }^{1}$ Department of Social Studies Education, University of Education, Winneba, Ghana, \\ ${ }^{2}$ Department of Accountancy, Sunyani Technical University, Sunyani, Ghana, ${ }^{3}$ Department of \\ Accounting and Finance, Christian Service University College, Kumasi, Ghana. \\ Email: ${ }^{1}$ kuranchiealf@yahoo.com, ${ }^{2}$ amaning_newman@stu.edu.gh, ${ }^{3}$ roanim@csuc.edu.gh
}

\begin{abstract}
The paper presents parents' views on how scholarships, grants and other financial assistance should be awarded to students to aid their schooling and results of a test of the vested interest and group identification models. The study was precipitated by the fact that more and more young people with academic potentials terminate their education prematurely due to financial encumbrances. The study was modeled along the quantitative paradigm. Stratified, systematic and simple random methods were respectively employed to select the communities, houses and subjects used for the study. Descriptive and inferential statistics were employed for the data analysis. Results demonstrate that generally parents are averse to giving financial assistance to students without recourse to their family financial standing. However, there were differences in the views of the elite and non-elite parents, and parents in urban and non-urban centres. Based on the results, it is concluded that the vested interest model explains the preference of the parents.
\end{abstract}

Keywords: Access to Education, Brilliant But Needy Students, Financial Assistance, Formal Education.

\section{Introduction}

Education is the cornerstone of and a lynchpin for nation's economic, social and political development of nations. It improves the productive capacity of society and enhances their political, economic and scientific institutions towards a sustainable development. Akanle (2007) postulates that the basis for real development of a nation starts with the development of human resource. It is through education that knowledge and skills, social conduct and character of individuals are developed and enhanced (Bhardwaj, 2016).

Formal education is instrumental in improving competencies of people hence aggregate increase in national productive capacity for economic growth and development. It is the human resource but not the material resources of a nation that determines the pace and character of its economic and social development (Forogalla, 1993). Harbison cited in Kuranchie (2006) postulates that it is education that generates the active capital that makes use of other factors of production. Human resource constitutes the ultimate basis for the wealth of nations. Capital and natural resources are passive factors of production; human 
beings are the active agents on how accumulated capital exploits natural resources, builds social, economic and political development.

Again, education imprints in people the values, attitudes, dispositions and skills, which are needed for qualitative change and this becomes agent of positive change of society (Opare, 1987). Fagerland and Saha (1989) also postulate that education is the agent for socialisation of young into the political culture; serves as the primary agent of the selection and training of political elite, and contributes to the political integration and the building of political consciousness. It is thus a reliable means of perpetuating political culture and values, and political structure of a nation via political socialisation (Agyeman, 1993). Empirical evidence depicts that the well-educated people are more likely to participate in political activities and to make informed decisions in the electoral process (Crowley, 2005).

It is profoundly clear that education is the means that give the youth a new vision and direction in life. It is, therefore, imperative to provide assistance to all capable citizens to enhance their accessibility to education as education is recognised as an elixir to the ills of under development. In a developing country like Ghana where a good portion of the citizenry is financially hard pressed, it is through financial aids that academically good children from disadvantaged backgrounds can pursue education to uplift themselves from their economic quagmire and to attain the United Nations Sustainable Development Goals (SDGs).

\section{Benefits of Education}

Education is a critical element of sustainable development of nations in a global competitive world. All shades of human talents need to be harnessed for the development of the economy to generate immeasurable benefits to the children and the nation at large. This is because education brings about both "private returns" and "public returns" (Weisbrod, 1962, Bellan, 2001, Levin, 2007). Private returns of education refer to the benefits that the individual derives from being educated while the public returns or social benefits concern the economic, social and political contributions that society derives from educated citizens. Private returns of education come in the form of direct financial returns, financial options, hedging options and non-market value (Levin, 2007). Education enhances students' decision making ability and reasoning competence (Means \& Voss, 1996). Education equips children with competencies that they require to be employed and live meaningful life. Most people who receive education gain employment and their economic well-being improves hence education promotes upward social mobility.

Social benefits of education are the social, economic and political contributions of educated people. According to Bellan (2001), investment in education yields high returns to both students and society. Implicitly, education yields broader social and economic benefits for individuals, their families and the society at large (Grossman, 2006). Education prepares the youth for their well-being and the welfare of society (Levin, 2007, Kayani, Akbar, Faisal, Kayani \& Ghuman, 2017). The benefits of education indirectly and externally go to the entire society by contributing to high productivity, positive social, political and cultural change and overall economic growth (Psachoropolous, 1994, Watternberger, 1994, Pannel, 2016). Some educated people contribute directly to traditional, religious bodies and institutional education endowment funds intended to promote education in the society. These contributions of the educated elites have neighbourhood effects on the community members.

Also, the taxes taken from educated citizens are used to acquire state properties, which citizens of the society enjoy. If more and more youth are equipped with functional pre- 
requisites through education, become gainfully employed and pay taxes, it would argument the state's tax revenue base for the development of the nation. The benefits of education, therefore, spill over to the society and serve as a buffer between individuals and social ills, which is good for societal progress and development. As an economist, Milton Friedman, asserted, the education of my child contributes to other people's welfare by promoting a stable and democratic society (Grossman, 2006). It is an incontrovertible fact that education guarantees for our future and if all capable individuals could be assisted to receive it, it would be good for all.

\section{Scholarships, Grants and other Financial Assistance}

Financing of education in the Ghana has been the responsibility of stakeholders in education. Particularly, the state and parents as major stakeholders have been financing greater part of education at all levels in the nation. Financial aid provided by individuals and groups has also been of immense contribution to the development of education in the nation-state since time immemorial. Quite recently, financial aid has grown in scope and forms. Besides the flagship Cocoabod scholarship instituted immediately after independence, there are a range of financial aids such as scholarship schemes, endowment funds and grants instituted by traditional communities, individuals, institutions, religious bodies and non-governmental organisations (NGO's) to help individuals and educational institutions to promote education in the country. Scholarships, grants and other forms of financial assistance have been extended to people to enhance their chances of pursuing education.

Traditional education endowment funds have been deeply involved in providing financial aid to Ghanaian students to pursue education at all levels of education. Some examples are the Otumfuo Education Fund and the Dormaaman Education Fund, which have been assisting children to have high education. Usually, traditional endowment funds use community membership as a determinant of qualification for receiving financial assistance but not necessarily financial needs. As much as it is worthy to help promote education in a traditional area by financially assisting inhabitants, the criterion for deciding who to benefit ought to be financial need so as to brighten the chances of brilliant but needy students to climb to the level that their intellectual capability can take them.

Some educational institutions also provide some sort of assistance to enable students to pursue education. Scholarships, grants, reduced fees and others are given by some educational institutions to help enhance students' education. Academic performance is usually used as the basis for determining who benefit from the educational institutions' financial assistance. In as much as this may promote competition and intrinsically make students learn assiduously, the brilliant but needy students' chances of getting financial assistance are not high. Hence, it does not promote equity in school access, retention and completion.

Some religious bodies have also instituted educational funds to extend financial assistance to children to enable them to pursue education. The principal criteria of qualification to benefit from the funds are usually membership of the religious body and financial needs. Although extending assistance to members of religious denominations invariably encourages attendance, the needy ought to be given a priority if social equity is to be achieved. Instructively, some wealthy individuals in some communities also do award scholarships and other forms of assistance to children in their communities who perform extremely well at final examinations to pursue high education. 
From the foregoing, it is crystal clear that financial aid is given based on different eligibility criteria such as merit, need and memberships. Some of these bases of offering assistance to pursue education do not work in favour of the poor who are endowed with academic prowess.

\section{The Models}

\section{Group Identification Model}

This model posits that individuals endorse policies, programmes and interventions that inure to the benefits of a group that they belong to but not necessarily that they would benefit from them. Some individuals endorse programmes and policies that intend benefiting the less privileged members of a group they belong to. The model posits that some individuals support such policies because they consider the plight of the group members but not for their selfaggrandisement. In the advance nations where social welfare packages exist, the enlightened minority group members, whether they experience financial hardship or not, identify and sympathize with the plight of their fellow members (Rafferty, 1989; Darwish \& Abdeldayem). Bodo (1989) asserts that in the United States, the well-to-do blacks tend to be highly predisposed to government interventions as they tend to benefit their black kits and kins. The well-educated people in the various communities, most of whom are in gainful employment would endorse granting of assistance to only brilliant but needy students if the group identification model would work.

\section{Vested Interest Model}

The vested interest model is a direct opposite to the group identification model. The model explains that people's attitude towards acceptance of policies, programmes and interventions in a society is contingent on the extent to which they would benefit from them (Hansenfeld $\&$ Rafferty, 1989). The model implies acceptance of social welfare facilities or packages stems from self-interest. According to the model, people willingly accept policies that inure to their benefit and reject those that will not benefit them (Steelman \& Powell, 1988). With this behaviour, even the well-placed individuals in the society would not endorse the idea that brilliant but needy students should be given priority when considering applications for assistance by scholarship schemes and education endowment funds.

\section{The Research Problem}

Given that education is regarded as very essential to the growth and development of individuals and society, all capable people need to be assisted to pursue education to a high level. Through education, people's talents are unearthed and sharpened to make them useful citizens in the society. In countries around the world, educational policies, reforms, initiatives and white papers exist to ensure that children of all social standings have access to formal education. Ghana as a nation-state is enjoined by local and international protocols and conventions to marshal resources to provide education for its citizens. It behoves the state to offer all children the opportunity to education to optimise their chances of success in life. Nonetheless, the stack reality is that the state alone cannot finance education in the country. This is because the other sectors of the economy compete for the limited resources available for efficient running of the state. Hence, parents shoulder part of the cost of education at the high levels. Parents bearing part of the cost of education gives the state the leverage to channel some resources to other sectors of the economy for the proper function of the 
nation. Nonetheless, the economic situation in the country does not make all parents financially viable to finance their children's education.

To ameliorate the financial burden of parents and to brighten the chances of children to enjoy education, the state, some institutions, religious bodies, NGOs and some public spirited individuals have been assisting in financing students' education. Assistance from such sources has prodigiously enabled many individuals to pursue education to high levels and some are in good social standing. A lot of well-placed people in the society have come from a very humble beginning through the assistance of these groups. Many are those who, during public functions and programmes, overtly testify to the monumental help that they received from these sources to reach the high social standing they find themselves. The assistance helps children whose parents are cash trapped to have education for their personal development and social advancement. This development has been helping to promote social equity in the society.

The assistance to pursue education comes in both cash and kind to enable students to achieve their educational goals in life. It is worthy to note that while some offer partial scholarships, others take full responsibilities of students' educational expenses including stipend. The assistance extended to students seems to ensure equalisation of educational opportunity to both children with and without the well-withal to pursue formal education. However, criteria for extending assistance to students vary considerably such as academic performance, financial need, traditional lineage, religious affinity, group membership, gender, disability and type of programme. There is no unison in the criteria for offering assistance to beneficiaries to pursue education. In situations where assistance is given not based on financial needs of applicants, there is feverish competition from children of both low and high income families. Except for those schemes which use financial need as a criterion for extending assistance, the chances of the children from poor homes are slim. In this situation, the children from disadvantaged backgrounds do not have high chance of receiving assistance to pursue education. Awarding assistance to brilliant but needy students would help improve access to education. Financial aid makes a difference in some categories of students' ability to progress to a high level in education. Studies show that financial aids have impact on students' access to education, retention and completion (St Johns, \& Starkey, 1995, Pascarella \& Terenzini, 2006). This may account for Girdwood (1999) position that scholarships should be given to those who cannot enrol due to financial difficulty to enable them pursue education. KarikariAbabio (1999) also supports the policy option of "positive discrimination" to enrol children from poor backgrounds into educational programmes. Positive discrimination policy is where brilliant but needy students are deliberately chosen to be assisted to enable them further their education to a high level. This is contrary to the arrangement where brilliant students whose parents can afford education are assisted as well thereby lowing the chances of brilliant but needy students to pursue education.

Parents, also as a major stakeholder in education, are usually not involved in taking some important decisions on education matters like educational financing and awarding some financial assistance. Their voices are usually not heard when such important decisions are taking. Again, parents, directly and/or indirectly, contribute to some of the endowment funds and scholarship schemes of the state, traditional areas and religious bodies. There is, however, paucity of research evidence on parents' views on the criteria relied on for determining eligibility for financial aids to pursue education. There also seems to be no evidence on parents' views on their involvement in deciding how financial assistance is awarded. This paper purported to fill the space in literature. 


\section{Rationale of the Study and Hypotheses}

The overarching goal of the study was to ascertain the extent of parents' acceptance of the bases of extending financial aid to students in the country. The study sought to unravel the agreeability on the bases of awarding assistance to students among parents living in different communities and parents with varying levels of education. The study tested two hypotheses, which are:

1. Ho: Parents in urban, semi-urban and rural communities do not differ in their preference for giving priority to brilliant but needy students when assisting children to pursue education.

2. Ho: Parents with post-secondary education, up to secondary education and no formal education do not differ in their preference for giving priority to brilliant but needy students when assisting children to pursue education.

\section{Methods and Materials Study Design}

The study was framed along the quantitative dimension and examined parents' preference for bases of assisting students to pursue education. The cross-sectional survey utilised parents whose children had completed or were in Senior High School (SHS). In Ghana, it is at the SHS level of education that financial aid institutions and benevolent individuals usually commence extending assistance to students to facilitate their access, retention and completion. It may probably be due to the fact that it is at this second echelon of education that most students go to boarding school in and outside their localities, which comes with high financial burden. Descriptive survey design was adopted in order to ascertain parents' perspectives on who should be assisted by financial aid groups. This design is helpful in providing accurate profile of research problem (Robson, 2002 cited in Kuranchie, 2016).

\section{Population and Sample}

Multi-stage sampling technique was adopted to select the study subjects. The region selected was stratified into urban, semi-urban and rural communities. In the various communities, some houses were systematically sampled and parents were randomly selected to participate in the study. The sampling techniques offered the towns, households and parents equal chance to participate in the study.

\section{Instrumentation and Measurement}

The study relied on primary data to describe the preference of the subjects with respect to bases that ought to be used in determining who benefits from assistance and also check differences in the parents' views on the issue. The data were gathered via administration of structured instrument. The self-administered questionnaire was made up of mainly closeended items. The questionnaire was developed, pre-tested and modified before administration. Cronbach alpha correlation was used to calculate the reliable co-efficient, which was found to be 0.82 . Also, expert judgment was used to check the face and content validity of the instrument.

The independent variables included level of education (No schooling, up to secondary education and post-secondary education) and community of residence (urban, semi-urban and rural). Dependent variables, on the other hand, included a measure of preference (using likert scale of measurement) for awarding financial assistance to students. 


\section{Data Analysis}

For data analysis, frequency counts and percentages were calculated to describe the sampled parents and their preference for the basis of extending assistance to students. To determine if there were differences among parents selected from the three communities and parents with various levels of education, One Way Analysis of Variance (ANOVA) was used. ANOVA is a technique used when the variables are on a continuum and the groups are more than two (Kuranchie, 2016). Further analysis using Tukey Post-hoc was done to locate where the difference was with respect to where significant difference was found.

\section{Results and Discussion}

The results of the study are presented in figures and tables. The bio-data of the respondents are presented in Figures while the main data which answered the research questions and hypotheses are displayed in Tables. Gender distribution of subjects of study is represented in figure 1.



\section{Figure 1: Distribution of Respondents by Gender}

The data analysis reveals that $61.3 \%$ of the sample were males and $38,7 \%$ were females. The results show that the male representation is higher than the female. The male dominance in the research may be due to the fact that in the Ghanaian traditional set-up, fathers are the heads of families and serve as spokespersons. Again, fathers shoulder a disproportionate chunk of family expenses including children's education. Hence, as the financial bearers of children's education, if both parents are present during a discourse on educational financing, male parents tend to stand in on behalf of their families. The distribution of respondents by community is in figure 2 .

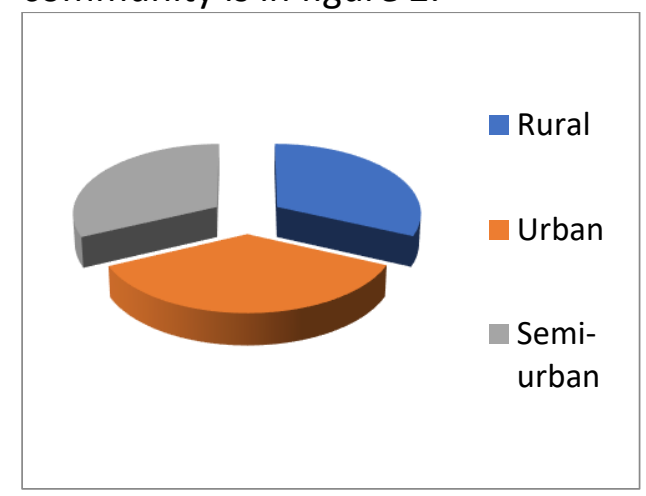

Figure 2: Distribution of Respondents by community of Residence

The results depict that about $36 \%$ of the subjects reside in urban communities, $31.2 \%$ live in semi-urban communities and approximately $32.8 \%$ stay in rural communities. The data 
analysis means that there is fair representation of the three categories of communities in the study.

Table 1 presents the results of statements showing parents' preference for assisting students.

Table 1: Statements of Positive Discrimination Policy

\begin{tabular}{|c|c|c|c|}
\hline Statement & Frequency & Percentage (\%) & Rank \\
\hline $\begin{array}{l}\text { Brilliant but needy students should be given a } \\
\text { priority when extending assistance to students. } \\
\text { All students should be given equal consideration }\end{array}$ & 402 & 78.98 & 1 \\
\hline $\begin{array}{l}\text { All students should be given equal consideration } \\
\text { when extending assistance to students. } \\
\text { Only academically good students should be }\end{array}$ & 51 & 10.02 & 2 \\
\hline $\begin{array}{l}\text { considered when extending assistance to } \\
\text { students. }\end{array}$ & 28 & 5.50 & 3 \\
\hline $\begin{array}{l}\text { Only students who pursue some special courses } \\
\text { should be given a priority when extending } \\
\text { assistance to students. } \\
\text { Only needy students, irrespective of the academic } \\
\text { prowess, should be considered when extending } \\
\text { assistance to students. }\end{array}$ & 15 & 2.95 & 4 \\
\hline Total & 509 & 100.00 & \\
\hline
\end{tabular}

The results illuminate that the majority of the subjects are supportive of the positive discrimination option of assisting students to pursue education. This is evidenced in the fact that 402 representing a whopping $78 \%$ of the subjects concurring that endowment funds, scholarship schemes and benevolent individuals ought to give priority to brilliant but needy students when they are determining beneficiaries of assistance.

Invariably, the majority of the subjects reject the notion that only brilliant students, all students, those who pursue some special types of programmes, and all needy but not brilliant students ought to be assisted to pursue education. They did not endorse the notion that all brilliant students, even if their parents can afford, should be assisted to pursue high education. They cannot fathom, for instance, why children who do not possess the academic wit and dexterity to pursue high education ought to be considered when deciding who should be helped. It may be their belief that using financial need as the only criterion to decide who should be assisted, without their academic aptitude may be a waste of resources and would not encourage seriousness in children. The overwhelming majority agreeing to assisting brilliant but needy students concurs with Girdwood (1999) and Karikari-Ababio (1999) assertion of positive discrimination. This policy option is to help children from disadvantaged backgrounds to pursue education to the level that their ability could carry them.

\section{Testing of Hypotheses}

The study hypothesized that parents in various communities would not differ in their acceptance of prioritising assistance to brilliant but needy students. Parents in the communities were not expected to differ in their preference for assisting students. The results are presented in Table 2. 
Table 2: Parents in Different Communities Preference for Assistance

\begin{tabular}{lccccc}
\hline Type of community & Df & M & SD & F & Sig. \\
\hline 1 & & 1.96 & .20 & & \\
2 & 2 & 1.98 & .15 & 3.142 & $.044^{*}$ \\
3 & & 1.92 & .28 & & \\
\hline
\end{tabular}

The results illustrate differences among the parents in the various communities with respect to their support for prioritising assistance for brilliant but needy students to enable them to also further their education. Significant differences were found, $F(2,509)=3.142, p<044$. Although most parents endorse the idea, difference existed in the views of parents in the various communities. The result of the analysis does not support the hypothesis that parents in the rural, semi-urban and urban communities do not differ in their support prioritising assistance to brilliant but need students, hence the hypothesis is rejected.

In view of the differences in the views of parents in the various communities, further analysis was carried out to locate where the difference lied. Tukey post-hoc analysis was used for the further exercise and the results are presented in Table 3.

Table 3: Post-hoc Analysis of Parents' Preference for Assistance

\begin{tabular}{cll}
\hline I & \multicolumn{1}{c}{ J } & \multicolumn{1}{c}{ (I-J) } \\
\hline Rural & Semi-urban & .04101 \\
Semi-urban & Urban & -.01794 \\
& Rural & .01794 \\
Urban & Urban & $.05694^{*}$ \\
& Rural & -.04101 \\
& Semi-urban & $-.15894^{*}$
\end{tabular}

The result unveils that the difference lies between parents in the rural communities, on the one hand, and those in the semi-urban and urban communities, on the other hand. More parents in the rural communities endorsed the proposition than those in the urban and semiurban communities did. This may be due to the fact that parents in rural communities have precarious financial situation than their counterparts in the semi-urban and urban centres where economic activities seem to be booming hence may not have the same financial needs. This study also hypothesised that parents with different levels of education would not differ in their preference for assistance to brilliant but needy students. The results of the analysis are displayed in Table 4.

Table 4: Parents with Varying Levels of Education Preference for Assistance

\begin{tabular}{cccccc}
\hline Level of Education & df & $\mathbf{M}$ & SD & $\mathbf{F}$ & Sig. \\
\hline 1 & & 1.54 & .50 & & \\
2 & 2 & 1.59 & .49 & 4.399 & $.019^{*}$ \\
3 & & 1.73 & .45 & & \\
\hline
\end{tabular}

The result of the data analysis does not support the hypothesis that parents with different levels of education differ in their support for positive discrimination policy. Significance difference was found, $F(2,509)=4.399, p<.019$. The results mean that respondents' agreement to prioritisation for brilliant but needy students differs among the parents with varying levels of educational attainment. In order to pinpoint where the difference lies, further analysis was conducted using Tukey post-hoc analysis. The results of the analysis are reported in Table 5. 
Table 5: Post-hoc Analysis of Parents' Preference for Assistance

\begin{tabular}{cll}
\hline I & \multicolumn{1}{c}{ J } & $(\mathbf{I}-\mathrm{J})$ \\
\hline No schooling & Secondary & $-18678^{*}$ \\
Secondary & Post-secondary & -.04779 \\
& No schooling & .04779 \\
Post-secondary & Post-secondary & .13797 \\
& No schooling & $.18578^{*}$ \\
& Secondary & .13799 \\
\hline
\end{tabular}

The results illuminate a difference among the subjects with different levels of education in terms of their preference for assisting children to pursue education. The results of the analysis indicate that the difference lies between parents with no formal education, on the one hand, and those with up to secondary education and post-secondary education, on the other hand. More parents with no formal education seemed to endorse the proposition more than those with formal education.

The outcomes of the two hypotheses indicate that the vested interest model but not the group identification model that tends to explain the behaviour of the well-educated and urban parents with respect to favouring brilliant but needy students when offering assistance to pursue education. More well-educated and urban parents, most of whom may be gainfully employed did not demonstrate much solidarity and sympathy with the less educated and rural parents, most of whom do not have irregular source of income. As such an idea will not benefit their dependents but rather only the downtrodden.

The results also seem to confirm the anecdotal evidence that in the country the highly educated parents, by virtue of their privileged positions, tend to push for assistance for their dependents. In such situations, the plight of the less or uneducated parents, most of whom domicile in rural settings and are not in reliable forms of employment, are not considered by their affluent counterparts when seeking financial assistance for their dependents.

\section{Conclusion}

Realising that the cost of education is highly unattainable for some families in the Ghanaian society and in their bid to contribute to reducing social inequality, some benevolent individuals and bodies have instituted and extended financial assistance to enable young people to have education. The bases for awarding assistance, however, differ. Parents also do not seem to be directly involved in deciding the bases of qualification for assistance in the schemes and funding agencies in the country. The results of the study have brought to the fore the views of parents on the subject.

Although the study found some differences in the views of parents in the urban, peri-urban and rural communities as well as parents with different levels of education, an overwhelming majority are positively predisposed to giving brilliant but needy students topmost priority when considering applications for granting assistance. Channeling assistance to brilliant but needy students is a means to help optimise most Ghanaian children's talents to improve themselves and the entire economy. It is also a good pathway to promoting social equity and to help achieve the SDGs on education.

Consequently, it would be advisable to have a shift in focus in awarding financial assistance to students to pursue education. To promote fair and just society, educational opportunities need to be provided to all children with academic prowess to develop their competence for personal and societal progress. 
The findings of the study need to be embraced by institutions, bodies, philanthropists, foundations, non-governmental organisations and public spirited individuals to inform their decisions and actions of assisting young ones to pursue education. The findings also provide policy makers and financial administrators of foundations, endowment funds, scholarship schemes, provident funds and benevolent individuals with the evidence that most parents prefer that brilliant but needy students need to be considered first when awarding financial assistance to students to pursue education.

Meta-analysis study may be conducted to ascertain the financial standing of parents of children who benefit from scholarships, grants and other assistance in the country to prove beyond anecdotal evidence that financial assistance usually goes to students whose parents can rather afford the cost of education.

Finally, given the fact that this study was conducted in only one region of the country, it must be replicated in the other regions to confirm the results. The study should set the stage and basis for a comprehensive study of the subject.

\section{References}

Agyernan, D. K. (1993). Sociology of education for African students. Accra: Black Mask Ltd..

Akanle, O. B. (2007). Socio-economic factors influencing students' academic performance in Nigeria, Freedom Library.

Bhardwaj, A. (2016). Importance of education in human life: A holistic approach. International Journal of Science and Consciousness, 2(2), 23-28.

Crowley, G. (2005). Non-profits and civic engagement: Benefits and challenges in building social capital. Pittsburgh, PA: Coro Center for Civic Leadership.

Darwish, S., \& Abdeldayem, M. M. (2019). Risk Management and Business Ethics: Relations and Impacts in the GCC. International Journal of Civil Engineering and Technology, 10(10), 489-504.

Fagerlind, I., \& Saha, L. I. (1989). Education and notional development: A comparative perspective. Exeter: BPE Wheatons Ltd.

Forojalla, S. B. (1993). Educational planning and development. London: St Martin's Press.

Girdwood, A. (1999). Tertiary education retch: An assessment. New York: World Bank.

Grossman, M. (2006). Education and no-market outcomes. In E. Hanushek and F. Welch (2006) Handbook of the Economics of Education. Elsevier: Maryland Height.

Hasenfeld, Y., \& Rafferty, R. A. (1989). The determinants of public attitudes towards the welfare state. Social Forces. 67 (I), 27-48.

Kayani, M. M., Akbar, R. A., Faisal, S., Kayani, A., \& Ghuman, A. (2017). Analysis of socio-

economic benefits of education in developing countries: An example of Pakistan. Bulletin of Education and Research, 3, 75-92.

Karikari-Ababio, M. (1999). MTEF In practice: A guide for educational administration. Accra: Ghana Education Service.

Kuranchie, A. (2006). Parents' preferred locus of responsibility for funding secondary education. Unpublished MPhil. Thesis. University of Cape Coast, Cape Coast.

Kuranchie, A. (2016). Research made easy. ( $2^{\text {nd }}$ ed.). Kumasi: Bookworm Publications.

Levin, H. M. (2007). The costs and benefits of an excellent education for all of America's children. New York, NY: Center for Benefit-Cost Studies in Education.

Opare. J. A. (1987). Education and rural development in Ghana: Bottlenecks, assets and 
strategies. An Unpublished M, Ed. Thesis, University of Cape Coast.

Pascarella, E. T., \& Terenzini, P. T. (2006). How college affects students: $A$ third decade of research. San Francisco, CA: Jossey-Bass.

Psachoropoulous, G. (1994). Rates of returns to investment in education Oxford: Oxford University Press

St. John, E. P., \& Starkey, J. B. (1995). An alternative to net price: Assessing the influence of prices and subsidies on within-year persistence. The Journal of Higher Education, pp, 66(2), 156-186.

Steelman, L. C., \& Powell, B. (1988). Doing the right thing. Race and parental locus of responsibility for funding college. Sociology of Education, 66 (4), I-8.

Wattenberger, J. (1994). Students fees and pubic: Social responsibility. The American College of Testing Programme, 143-153.

Weisbrod, B. A. (1962). Education and investment in human capital. Journal of Political Economy, 106-123. 